\title{
Strategies for Enhancing Roadside Motor Vehicle Mechanics on Basic Computer Skills for Effective Manipulation of Automotive Digital Diagnostic Tools in Nsukka Urban of Enugu State
}

\author{
Olaitan Olawale Opeyemi*, Ujevbe Oke Benjamin \\ Department of Industrial Technical Education, University of Nigeria, Nsukka, Nigeria
}

Email address:

olawale.olaitan@unn.edu.ng (O. O. Opeyemi)

${ }^{*}$ Corresponding author

To cite this article:

Olaitan Olawale Opeyemi, Ujevbe Oke Benjamin. Strategies for Enhancing Roadside Motor Vehicle Mechanics on Basic Computer Skills for Effective Manipulation of Automotive Digital Diagnostic Tools in Nsukka Urban of Enugu State. American Journal of Mechanical and Industrial Engineering. Vol. 5, No. 6, 2020, pp.71-77. doi: 10.11648/j.ajmie.20200506.11

Received: June 22, 2020; Accepted: July 15, 2020; Published: December 11, 2020

\begin{abstract}
This study analyzed strategies for enhancing roadside motor vehicle mechanics on basic computer skills for effective manipulation of automotive digital diagnostic tools using a 4-point scale questionnaire, validated by three experts, on 30 master roadside motor vehicle mechanics and 20 apprentice roadside motor vehicle mechanics in Nsukka urban of Enugu state. The study was guided by three research questions. Descriptive survey research design was employed for the study. A reliability co-efficient of 0.95 was obtained using Cronbach alpha test. Mean and Standard Deviation were used to analyze data collected. Findings of the study revealed among others that roadside motor vehicle mechanics do not possess the needed computer skills for the effective manipulation of automotive digital diagnostic tools and this poses challenges to the diagnosis, repair and maintenance of modern vehicles. The current maintenance practice falls below international best practice required for effective manipulation of automotive digital diagnostic tools; as a result, roadside motor vehicle mechanics loss daily patronage from customers who use modern vehicles. The study recommended among others that stakeholders in collaboration with leaders of roadside motor vehicle mechanics should continually organize appropriate training and retraining programmes for up skilling of roadside motor vehicle mechanics in Nsukka urban of Enugu state.
\end{abstract}

Keywords: Roadside Motor Vehicle Mechanics, Basic Computer Skills, Sensors, Actuators, On-Board Diagnostic, Automotive Digital Diagnostic Tools

\section{Introduction}

Over $70 \%$ of vehicles used in Nigeria are imported from Europe, America and Asia through Nigeria Port Authority (NPA) or through Cotonou in neighboring Benin Republic by foreign used vehicle dealers, independent sales men and individual buyers. These foreign used vehicles also known as "Tokunbo", incorporates electronic and computer related components called sensors and actuator and can only be found in modern vehicles. Several studies have shown that roadside motor vehicle mechanics encounter great difficulties trying to diagnose and repair simple faults in modern vehicles. One reason among others noted by News Agency of
Nigeria (NAN), documented in Vanguard, was the inability of roadside motor vehicle mechanics to use computers and other automotive digital diagnostic tools for vehicle diagnosis, repair and maintenance. In the same report, NAN said, customers do not feel safe patronizing roadside motor vehicle mechanics who do not use computers for vehicle diagnosis, repair and maintenance [3]. According to Maigida and Francis [13], most roadside motor vehicle mechanics do not possess the required basic computer skills for the effective manipulation of automotive digital diagnostic tools and this has further worsened the satiation for them as numerous sensors and actuators are now incorporated in modern vehicles.

Sensors according to Cristian. G, Daniel. L, Cristian B and 
Juan. L [5], are electrical devices composed of sensitive cells that measures a concrete physical parameter such as light, temperature, sound, movement or any other fluctuations in the environment. Automobiles comprise numerous sensors that serves divers purposes and located at different places around the vehicle [8]. Throttle position sensor, manifold absolute pressure sensor [4] are some examples of sensors in automobile. As observed by Schilling. R, Jordan F, Rochford. $\mathrm{G}$ and Nist. A [16], actuators in automobiles are devices that converts electrical signals to actions. Injectors, fuel pump, brake pads, among others, are some examples of actuators. It is quit unfortunate that roadside motor vehicle mechanics in Nsukka urban of Enugu state cannot use a computer to access these devices. All automotive sensors and actuators are controlled by a built-in computer system called On-Board Diagnostics (OBD).

OBD system consists of an ECU (Electronic Control Unit), which uses input from various sensors (e.g., oxygen sensors) to control the actuators (e.g., fuel injectors) to get the desired performance. As explained by the United State Environmental Protection Agency, [17] on-board diagnostics (OBD) is an onboard computer based system applying numerous vehicle sensors to monitor the status of some components, especially those designed for emission control such as the Electronic Control Unit (ECU), catalytic converter, and alert the driver with an indicator light on the dash board in case of any malfunctions that may lead to high emissions. The agency added that OBD system is of two kinds, OBD I and OBD II. OBD I refers to the first generation systems designed to monitor manufacturer-specific systems on vehicles built from 1981 to 1995 and accessing diagnostic information typically requires getting a tool for every different vehicle make, while, OBD II is the second generation systems designed to alert the driver when emission levels are greater than 1.5 the car as it was originally certified by the EPA. Vehicles that incorporate these devices are sources of headaches to roadside motor vehicle mechanics in Nsukka urban of Enugu state and Nigeria at large.

In Nigeria, roadside motor vehicle mechanics are very strategic when it comes to providing vehicle diagnosis, repairs and maintenance services. These services range from assisting stranded motorists along the road, by manually diagnosing and repairing vehicle faults immediately or moving the vehicle to a safe place off the road where they can systematically locate and repair possible faulty components. Roadside motor vehicle mechanics [12] are those who possess skills set involving visual, hearing, smelling and feeling abilities, adopt and also apply the 'try and error' approach in detecting malfunctions and repairs of almost all automobiles. Reports has it that about 90 per cent of over 5,000,000 roadside motor vehicle mechanics in Nigeria use "trial and error" method to diagnose the problems of automobiles. As the technology needed by roadside motor vehicle mechanics to diagnose, repair and maintain modern vehicles advances, the problems they face has also compounded as the trial and error skill set alone are insufficient for optimal diagnosis, repair and maintenance of
OBD II enabled vehicles, i.e., vehicles that incorporates OBD II system and requires computer based-software to enable interaction between the vehicle and the roadside motor vehicle mechanic, one of which is the Alldata [13]. This situation is the "state of the art" regarding roadside motor vehicle mechanics in Nsukka urban of Enugu State particular.

The Alldata is an automotive software that provides vehicle manufacturers' diagnostic and repair information in a single, reliable source which can be read off from a lap top computer screen. It is used on OBD II enabled vehicles and requires some competencies in using a lap top computer for several operations such as identify and lunching the software in the computer, navigating through sections in the software. Studies have shown that roadside motor vehicle mechanics in Nigeria can avoid been thrown out of the labour market and also boost daily patronage by simply acquiring some basic computer skills relevant in the effective manipulation of digital diagnostic tools.

Basic computer skills as noted by Laura (2016), facilitate work and reduce the time required to perform tasks in work places. Some basic computer skills relevant to roadside motor vehicle mechanics include powering and shutting down a lap top computer; navigating through the computer interphases/applications; surfing the internet; sending and receiving e-mails; updating antivirus and similar software; downloading upgraded version of vehicle instruction manual from specific websites; etc. According to the Director General, National Automotive council in Nigeria, Engineer Aminu Jalal in 2014, noted that acquiring the afore mentioned skills can reduce technophobic tendencies and also provide better platform upon which roadside motor vehicle mechanics can relate with automotive digital diagnostic tools for fault diagnosis and repairs on OBD II enabled vehicles.

Automotive digital diagnostic tools are tools employed when working on OBD II enabled vehicles for diagnosis, repair and maintenance of the ECU. They are very robust in reading and clearing trouble codes, reading data streams and other special features, Lunch Professional and Autobus examples of automotive digital diagnostic tools. The manipulation of automotive digital diagnostic tools [6], requires some skills for its efficient usage which include identifying Lunch Professional and Autobus; use the Lunch to diagnose the power train, chassis, engine; locating and identifying pin configurations for Data Link Connector (DLC); connecting scan tools to the OBD II connector; interpreting and clearing Diagnostic Trouble Codes (DTCs); interpreting Malfunction Indicator Light (MIL); among others. These skills are very important in OBD enabled vehicle repairs and maintenance in Nigeria and particularly, in Nsukka urban of Enugu.

The advent of vehicles in the country incorporated with OBD II technology is the genesis of the significant lacuna between roadside motor vehicle mechanics and their competencies in handling such vehicles as they lack the technical skills needed to diagnose, repair and maintain modern vehicles. Currently in Nigeria, it is a general 
knowledge that a large proportion of the roadside motor vehicle mechanics, both the masters and apprentices find it extremely difficult to diagnose, repair and maintain OBD II enabled vehicles. Due to this, customers who use such vehicles seek help in standardized auto-workshops around the country regardless of the high charges they may have to pay. Indeed, the situation is posing serious threats to most roadside motor vehicle mechanics in the country some of which have been thrown out of business. According to Vanguard in 2014 [15], over two million roadside motor vehicle mechanics in Nigeria may be forced into the labour market, because the type of vehicles they are conversant with are gradually being phased out of the market, owing to global rapid development in technology and this will affect the economy significantly.

The problems faced by the roadside motor vehicle mechanics in the country as touching the repair and maintenance of OBD II enabled vehicles could be attributed to reasons such as, technophobia resulting to lack of interest in operating a lap top computer, inability to manipulate diagnostic tools, waste of time in detecting faults, damage to engines without the use of diagnostic machines in detecting faults and consequently loss of customers, poor attitudes and behaviour of today's motor vehicles mechanics among others. Another very significant problem faced by roadside motor vehicle mechanics is their inability to use the software, Alldata. Roadside motor vehicle mechanics actually find it very difficult to attempt the use of a personal computer on which the software is installed to interpreting Diagnostic Trouble Codes (DTCs) obtained from diagnosing modern vehicle fault using scanners and comparing them with manufactures' standard. Hence, the need to develop strategies for enhancing roadside motor vehicle mechanics on basic computer skills for effective manipulation of automotive digital diagnostic tools in Nsukka urban of Enugu State.

\subsection{Purpose of the Study}

The general purpose of this study is find out strategies for enhancing roadside motor vehicle mechanics on basic computer skills for effective manipulation of automotive digital diagnostic tools in Nsukka urban of Enugu State. Specially, the study seeks to:

1. Find out the level of awareness of roadside motor vehicle mechanics on basic computer skills for effective manipulation of automotive digital diagnostic tools in Nsukka urban of Enugu State.

2. Determine the skills possessed by roadside motor vehicle mechanics in the effective manipulations of automotive digital diagnostic tools in Nsukka urban of Enugu State.

3. Determine the basic computer skills required by roadside motor vehicle mechanics for the effective manipulations of automotive digital diagnostic tools in Nsukka urban of Enugu State.

4. Develop strategies for enhancing roadside motor vehicle mechanics on basic computer skills for effective manipulations of diagnostic tools in Enugu State.

\subsection{Research Question}

1. What is the level of awareness of roadside motor vehicle mechanics on basic computer skills for effective manipulation of automotive digital diagnostic tools in Nsukka urban of Enugu State?

2. What are the skills possessed by roadside motor vehicle mechanics in the effective manipulations of automotive digital diagnostic tools in Nsukka urban of Enugu State?

3. What are the basic computer skills required by roadside motor vehicle mechanics for the effective manipulations of automotive digital diagnostic tools in Nsukka urban of Enugu State?

4. What are the strategies for enhancing roadside motor vehicle mechanics on basic computer skills for effective manipulations of diagnostic tools in Enugu State?

\section{Methodology}

The descriptive survey research design was employed in this study in order to describe, analyze and interpret the findings of the study for generalization. A survey research design as explained by Anyakoha [2] uses questionnaires, interviews, observations in order to determine the opinions, attitudes, perceptions, preferences of persons. The population of the study was made up of 190 roadside motor vehicle mechanics in Nsukka urban of Enugu state. A sample size of 50 roadside motor vehicle mechanics comprising 30 masters and 20 apprentices roadside motor vehicle mechanic with 1year experience under training in the area of the study was used for this study by adopting the purposive sampling technique, also called judgment sampling. It is a non-random technique that does not need underlying theories or a set number of participants but they are deliberately selected due to the qualities they possess [9]. A closed ended questionnaire validated by three experts was used for data collection. The reliability coefficient of the questionnaire determined using Cronbach alpha method was 0.94 .

Data collected was done by the researcher alone and were analyzed using descriptive Statistics from the Statistical Package for the Social Sciences (SPSS), release 23.0 for Windows Operating System. The data collected from the respondents were analyzed using Mean and Standard deviation. The decision rule for the research questions was based on mean value of 2.50 for each item remarks, while the standard deviations was used to interpret the mean values.

\section{Data Presentation and Analysis}

The data collected was analysed using mean and standard deviation and were presented in tables in accordance with the corresponding research questions.

Research Question 1: what is the level of awareness of roadside motor vehicle mechanics on basic computer skills for effective manipulation of automotive digital diagnostic tools in Nsukka urban of Enugu State? 
Table 1. Mean and Standard Deviation of the level of awareness of roadside motor vehicle mechanics on basic computer skills for effective manipulation of automotive digital diagnostic tools in Nsukka urban of Enugu State.

\begin{tabular}{|c|c|c|c|c|}
\hline $\mathbf{S} / \mathbf{N}$ & $\begin{array}{l}\text { Level of awareness of roadside motor vehicle mechanics on basic computer skills for } \\
\text { effective manipulation of automotive digital diagnostic tools }\end{array}$ & $\begin{array}{l}\text { Mean } \\
\bar{X}\end{array}$ & SDV & Remarks \\
\hline 1. & Knowledge of a lap top computer & 3.26 & 0.92 & Aware \\
\hline 2. & Knowledge of a lap top computer major components & 3.16 & 0.93 & Aware \\
\hline 4. & Knowledge of a lap top lap top computer software applications & 2.64 & 1.06 & Aware \\
\hline 5. & Knowledge of a lap top computer capabilities & 3.20 & 0.73 & Aware \\
\hline 6. & Knowledge of a lap top computer in automobile & 3.38 & 0.73 & Aware \\
\hline 8. & Knowledge of the Windows platforms 7,8 and 10 & 1.98 & 0.92 & Not Aware \\
\hline 9. & Knowledge of internet & 2.46 & 0.81 & Not Aware \\
\hline 10. & Knowledge of Wi-Fi & 1.70 & 0.86 & Not Aware \\
\hline 11. & Knowledge of On-Board Diagnostics II & 2.90 & 0.68 & Aware \\
\hline 12. & Knowledge of scanning devices and code readers in automobile & 3.26 & 0.77 & Aware \\
\hline 13. & Knowledge of sensors & 3.72 & 0.57 & Highly Aware \\
\hline 14. & Knowledge of actuators & 3.74 & 0.52 & Highly Aware \\
\hline 15. & Knowledge of Electronic Control Unit (ECU) & 3.48 & 0.61 & Aware \\
\hline 17. & Knowledge of electronics in automobile & 3.44 & 0.64 & Aware \\
\hline 18. & Knowledge of Lunch x431 Professional & 2.54 & 0.97 & Aware \\
\hline 19. & Knowledge of Autobus & 2.34 & 1.06 & Not Aware \\
\hline 20. & Knowledge of Lunch x431/Autobus V30 capabilities & 2.68 & 0.84 & Aware \\
\hline
\end{tabular}

Source: Field Study, 2016 Grand mean $=2.96$

Data presented in table 1 above, reveals that the generality of the respondents are aware/highly aware on 16 items with mean ratings and standard deviations between 2.54 to 3.74 and 0.6 to 1.06 respectively. Although, they are not aware on 4 items with mean ratings and standard deviations between 1.70 to 2.46 and 0.81 to 1.06 respectively. However, the grand mean of 2.96 indicates that roadside motor vehicle mechanics are aware of basic computer skills for effective manipulation of automotive digital diagnostic tools.

Research Question 2: what are the basic computer skills possessed by roadside motor vehicle mechanics in the effective manipulations of automotive digital diagnostic tools in Nsukka urban of Enugu State?

Table 2. Mean and Standard Deviation of the basic computer skills possessed by roadside motor vehicle mechanics in the effective manipulations of automotive digital diagnostic tools in Nsukka urban of Enugu State.

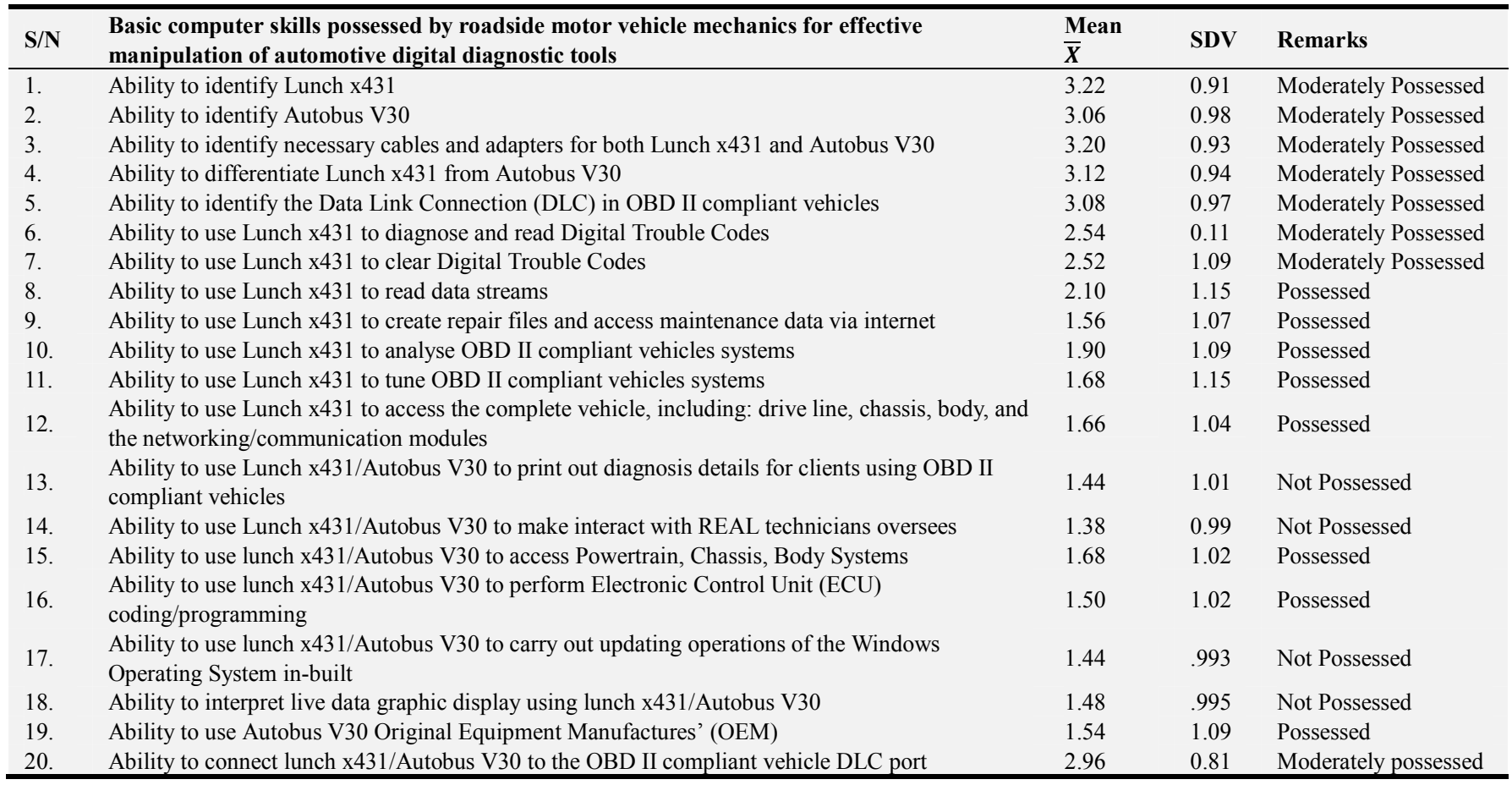

Source: Field Study, 2016 Grand mean $=2.15$ 
It is revealed from the above table that the respondents agreed on 8 items with mean ratings and standard deviations between 2.52 to 3.22 and 0.11 to 1.09 respectively. Though, they disagreed/strongly disagreed on 12 items between 1.44 to 2.10 and 0.99 to 1.15 respectively. However, the grand mean of 2.15 indicates that roadside motor vehicle mechanics do not possess basic computer skills for effective manipulations of automotive digital diagnostic tools.

Research Question 3: what are the basic computer skills required by roadside motor vehicle mechanics for the effective manipulations of automotive digital diagnostic tools in Nsukka urban of Enugu State?

Table 3. Mean and Standard Deviation the basic computer skills required by roadside motor vehicle mechanics for the effective manipulations of automotive digital diagnostic tools.

\begin{tabular}{|c|c|c|c|c|}
\hline $\mathbf{S} / \mathbf{N}$ & $\begin{array}{l}\text { Basic computer skills required by roadside motor vehicle mechanics for effective } \\
\text { manipulations of automotive diagnostic tools }\end{array}$ & $\begin{array}{l}\text { Mean } \\
\end{array}$ & SDV & Remarks \\
\hline 1. & Boot and shutdown a lap top computer & 3.96 & 0.20 & Highly Required \\
\hline 2. & Lap top computer software navigation & 3.96 & 0.20 & Highly Required \\
\hline 3. & Lunching and closing a software & 3.92 & 0.27 & Highly Required \\
\hline 4. & Software installations & 3.90 & 0.30 & Highly Required \\
\hline 5. & Key programming and reprogramming & 3.74 & 0.56 & Highly Required \\
\hline 6. & Ability to download, update vehicle data using Windows various platforms & 3.82 & 0.39 & Highly Required \\
\hline 8. & Computer appreciation, care/maintenance of similar digital devices & 3.94 & 0.24 & Highly Required \\
\hline 9. & Ability to write with stylus effectively & 3.84 & 0.42 & Highly Required \\
\hline 10. & Ability to manage personal data and use online dictionary & 3.90 & 0.61 & Highly Required \\
\hline
\end{tabular}

Source: Field Study, 2016 Grand mean $=3.89$

Table 3 reveals that respondents highly require items 1 to 10 with mean ratings and standard deviations between $3.74-$ 3.96 and 0.20 to 0.61 respectively. In the same vein, the grand mean of 3.89 indicates that roadside motor vehicle mechanics highly require basic computer skills for effective manipulations of automobile digital diagnostic tools.

Research Question 4: what are the strategies for enhancing roadside motor vehicle mechanics on basic computer skills for effective manipulations of diagnostic tools in Enugu State?

Table 4. Mean and Standard Deviation of the strategies for enhancing roadside motor vehicle mechanics on basic computer skills for effective manipulations of diagnostic tools.

\begin{tabular}{|c|c|c|c|c|}
\hline $\mathbf{S} / \mathbf{N}$ & $\begin{array}{l}\text { Strategies for enhancing roadside motor vehicle mechanics on basic computer skills for effective } \\
\text { manipulations of automotive diagnostic tools }\end{array}$ & $\begin{array}{l}\text { Mean } \\
\end{array}$ & SDV & Remarks \\
\hline 1. & On-the job training & 3.94 & 0.24 & SA \\
\hline 2. & Weekend workshop training for two months & 3.82 & 0.39 & SA \\
\hline 4. & National Automotive Council to upskill RMVM in OBD skills & 3.80 & 0.49 & SA \\
\hline 5. & National Automotive Council collaboration with tertiary institutions & 3.24 & 0.85 & A \\
\hline 6. & National Automotive Council collaboration with foreign bodies & 3.98 & 0.14 & SA \\
\hline 8. & Mentoring methods & 3.90 & 0.30 & SA \\
\hline 9. & National Automotive Council in collaboration with Small and Medium Enterprises Development Agency of Nigeria & 3.48 & 0.58 & A \\
\hline 10. & Roadside motor vehicle mechanics enroll for mechatronic courses & 3.24 & 0.89 & A \\
\hline
\end{tabular}

Source: Field Study, 2016 Grand mean $=2.96$

The table 4 above indicates respondents agreed/strongly agreed on items 1 to 10 with mean ratings and standard deviation between 3.24 to 3.98 and 0.14 to 0.89 respectively. The grand mean obtained as 3.71 indicates that the respondents strongly agreed to the stated strategies on basic computer skills for effective manipulation of automotive digital diagnostic tools.

\section{Discussions of Findings}

The findings clearly showed that $60 \%$ of the items on basic computer skills for effective manipulation of automotive digital diagnostic tools ranged from aware to highly aware by roadside motor vehicle mechanics in Nsukka urban of Enugu state. However, on the remaining $40 \%$ of the items, respondents indicated not aware. That is to say, most roadside motor vehicle mechanics are either aware or highly aware of basic computer skills for effective manipulation of automotive digital diagnostic tools. This finding is in line with Edunyah (2015) who observed that most motor vehicle mechanics seem not to be able to use most automotive digital diagnostic tools for diagnosis, repair and maintenance of modern vehicles but seem to be aware of some basics computer skills for effective manipulation of automotive digital diagnostic tools.

The result of the study also showed that most respondents barely possessed the basic computer skills for effective manipulation of automotive digital diagnostic tools on 12 items, except 8 which was agreed to. This corroborated with the report of Ezeama. A, Obi. P and Ede. E (2016) which 
indicates most roadside motor vehicle mechanics lack the basic computer skills required for the effective manipulation of automotive digital diagnostic tools. It is also in line with Maigida and Francis [13] who noted that most roadside motor vehicle mechanics do not possess the required basic computer skills for the effective manipulation of automotive digital diagnostic tools and this has further worsened the satiation for them as numerous sensors and actuators are now incorporated in modern vehicles.

The further finding revealed that respondents highly require the basic computer skills for effective manipulation of automotive digital diagnostic tools. This assertion is in congruence with Roner [10] who said roadside motor vehicle mechanics requires a high level of diagnostic skill because of the increasing sophistication of the technology used in modern vehicle systems. More so, the average vehicle may have 30 or more microprocessor-controlled devices [14].

Also, the finding revealed that all the items in the cluster on strategies for enhancing roadside motor vehicle mechanics on basic computer skills for effective manipulation of diagnostic tools ranging from agreed to strongly agree. This connote that stakeholders concerned with ensuring roadside motor vehicle mechanics are provided with the relevant technical skills and cognitive skills in the use of automotive digital diagnostic tools of international standard should ensure the implementation of training and retraining programmes for roadside motor vehicle mechanics to enable them effectively handle modern vehicles in Nigeria. This finding is in agreement with Roner who noted that automotive systems are very different from the automotive systems of thirty years ago. Hence, today's roadside motor vehicle mechanics require a large amount of education and training strategies on each automotive system to develop the high-level diagnostic troubleshooting skills needed to work on today's automotive technologies.

\section{Conclusion}

It was discovered that most roadside motor vehicle mechanics in Nsukka urban of Enugu state, are aware of some basic computer skills required for the automotive digital diagnostic tools but seriously lack the skills required to manipulate them for diagnosis, repair and maintenance of modern vehicles. One of the reasons for this as noted by Roner is the lack of training programmes organized for these set of individuals to become stable in handling these automotive digital diagnostic tools for effective repairs of modern vehicles. To this end, it therefore mean that efforts should be made by stakeholders in the direction of not just planning but as well implementing a realistic training programme where roadside motor vehicle mechanics who want it, need it and can make profit by it, can be trained thereby enabling them acquire and possibly develop modern work skills of international standard needed for the effective repair and maintenance of modern vehicles as found in Nigeria today, thus boosting their job performance and satisfaction, daily customer patronage as well in the efficient handling of simple and complex faults on modern vehicles using recent automotive digital diagnostic tools.

\section{Recommendations}

In line with the findings of this study, it is recommended that:

1. Most roadside motor vehicle mechanics require basic computer skills for the effective manipulation of automotive digital diagnostic tools used to repair modern vehicle.

2. Stakeholders who are saddled with the job of ensuring standards in automotive diagnosis, repair and maintenance in Nigeria should collaborate with leaders of roadside motor vehicle mechanics so as to develop appropriate strategies for training and retraining them on the in-depth knowledge of recent technologies needed for the manipulation of automotive digital diagnostic tools used to repair modern vehicle.

\section{References}

[1] Africa's Next Automotive Hub. (2016). Retrieved from https://www.pwc.com/ng/en/assets/pdf/africas-nextautomotive-hub.pdf

[2] Anyakoha, E. U. (2009). Developing research skills: Concept and conceptual framework. Nsukka: Great AP Express Publishers Ltd.

[3] Auto mechanics seek computer training to repair modern vehicles - Survey (2013, October 16). Retrieved from http://www.vanguardngr.com/2013/10/auto-mechanics-seekcomputer-training-repair-modern-vehicles-survey/

[4] Davidson, M. (2016). Automotive sensors. Retrieved from http://www.auto-repair-

help.com/automotive_maintenance/automotive_sensors.php

[5] Cristian. G., Daniel. L., Cristian B. \& Juan. L. (2017). A review about smart objects, sensors, and actuators! International journal of interactive multimedia and artificial intelligence, 1-5, DOI: 10.9781/ijimai.2017.431.

[6] Dentom, T. (2006). Advanced automotive fault diagnosis $\left(2^{\text {nd }}\right.$ ed.). United Kingdom: Elsevier Ltd.

[7] Erjavec, J. (2009). Automotive technology: A system approach $\left(5^{\text {th }}\right.$ ed.). Canada: Nelson Education Ltd.

[8] Fleming, W. J. (2002). Overview of automotive sensors Retrieved http://ieeexplore.ieee.org/document/983469/?part=1

[9] Etican, I., Musa, S., \& Alkassim, R. (2015). Comparison of convenience sampling and purposive sampling. American journal of theoretical and applied statistics, 5 (1), 1-4 10.11648/j.ajtas.20160501.11.

[10] Roner, C. K. (2014). Improving automotive troubleshooting skills. Digital Commons@ USU All Graduate Plan B and other Reports Graduate Studies. Utah State University: Logan, Utah. 
[11] Latzko, L. (2015). The advantages of being computer literate in the workforce. Retrieved from $\mathrm{http} / / /$ smallbusiness.chron.com/advantages-being-computerliterate-workforce-27703.html

[12] Lindsay, C. (2013). How car will get more helpful. Retrieved from www.autorcar.com

[13] Maigida, J. F., Francis, A. (2014). An analysis of issues in automobile mechanics' workplaces in Nigeria. International Journal of Vocational Education \& Training. 22 (2), 78-92.

[14] Motavalli, J. (2010, February 4). The dozens of computers that make modern cars go (and stop). The New York Times. New York. Retrieved April 15, 2014, from http://www.nytimes.com/2010/02/05/technology/05electronics .html?_r=0
[15] Nnabugwu, F. (2014, July 15). National Automotive Council trains 1,000 Mechanics in Abuja. Vanguard. Retrieved from http://www.vanguardngr.com/2014/07/nac-trains-1000mechanics-abuja/

[16] Schilling, R., Jordan, F., Rochford, G., and Nist, A. (2016). Automotive OBD-II device generating navigational information. Retrieved from http://www.freepatentsonline.com/y2016/0084657.html

[17] U.S. Environmental Protection Agency (U.S. EPA), 2015. OnBoard Diagnostics (OBD). Available at http://www3.epa.gov/obd/index.html 